\title{
Influential journals in health research: a bibliometric study
}

\author{
José M. Merigó and Alicia Núñez ${ }^{*}$ [D
}

\begin{abstract}
Background: There is a wide range of intellectual work written about health research, which has been shaped by the evolution of diseases. This study aims to identify the leading journals over the last 25 years (1990-2014) according to a wide range of bibliometric indicators.

Methods: The study develops a bibliometric overview of all the journals that are currently indexed in Web of Science (WoS) database in any of the four categories connected to health research. The work classifies health research in nine subfields: Public Health, Environmental and Occupational Health, Health Management and Economics, Health Promotion and Health Behavior, Epidemiology, Health Policy and Services, Medicine, Health Informatics, Engineering and Technology, and Primary Care.

Results: The results indicate a wide dispersion between categories being the American Journal of Epidemiology, Environmental Health Perspectives, American Journal of Public Health, and Social Science \& Medicine, the journals that have received the highest number of citations over the last 25 years. According to other indicators such as the $h$-index and the citations per paper, some other journals such as the Annual Review of Public Health and Medical Care, obtain better results which show the wide diversity and profiles of outlets available in the scientific community. The results are grouped and studied according to the nine subfields in order to identify the leading journals in each specific sub discipline of health.

Conclusions: The work identifies the leading journals in health research through a bibliometric approach. The analysis shows a deep overview of the results of health journals. It is worth noting that many journals have entered the WoS database during the last years, in many cases to fill some specific niche that has emerged in the literature, although the most popular ones have been in the database for a long time.
\end{abstract}

Keywords: Health, Bibliometrics, Journals, Web of Science

Abbreviations: GR, Global Ranking; WoS, Web of Science

\section{Background}

The scope of public health history is dynamic and has been shaped by the evolution of diseases. In the last decades, health research has moved from the study of sanitary reforms and the control of infectious diseases, to the study of the impact of epidemic and contagious diseases, and to the inclusion of social action initiatives taken in response of epidemic disasters. Thus, the scope of health research has been expanded and broadened from a range of intellectual disciplines

\footnotetext{
*Correspondence: anunez@fen.uchile.cl

Department of Management Control and Information Systems, School of Economics and Business, Universidad de Chile, Diagonal Paraguay 257, Office 2004, Santiago, Chile
}

(c) 2016 The Author(s). Open Access This article is distributed under the terms of the Creative Commons Attribution 4.0 International License (http://creativecommons.org/licenses/by/4.0/), which permits unrestricted use, distribution, and reproduction in any medium, provided you give appropriate credit to the original author(s) and the source, provide a link to the Creative Commons license, and indicate if changes were made. The Creative Commons Public Domain Dedication waiver (http://creativecommons.org/publicdomain/zero/1.0/) applies to the data made available in this article, unless otherwise stated.

including the study of health economics [1], and social and political relations of health [2]. These intellectual contributions have been well documented in a range of professional journals.

The oldest continuously published medical journal was introduced in 1812 by the Massachusetts Medical Society and was called The New England Journal of Medicine and Surgery and the Collateral Branches of Science, which in 1828 became The Boston Medical and Surgical Journal and later The New England Journal of Medicine. From that period of time many other medical associations and journals started to emerge including the Journal of the American Medical Association in 1883, Milbank Quarterly in 1923, Public Health Economics and Medical 
Care Abstracts (today's Medical Care Research and Review) in 1944, Inquiry and Medical Care in 1963, Health Service Research in 1966, and Social Science and Medicine in 1967. Healthcare Financial Management and the International Journal of Health Services appeared in the 70's, and also the Journal of Health Politics, Policy and Law, Health Care Management Review, Hospital and Health Services Administration, the Journal of Ambulatory Care Management and, and Health Care Financing Review. In the 80's there was an explosion of new journals such as the Journal of Public Health Policy, Health Affairs, Advances in Health Economics and Health Services Research, Health Care Strategic Management, Frontier of Health Services Management, International Journal of Technology Assessment in Health Care, International Journal of Health Planning and Management, Health Care Financing Review, and the International Journal for Quality in Health Care. The first issue of the Journal of Health Services Research and Policy was published in 1996, and in the 2000s the Health Services and Outcomes Research Methodology appeared [3].

For this reason, there is a wide range of intellectual work written about health research and it is time to evaluate its development and main characteristics. Bibliometric analysis can help determine trends and patterns of publications within a research discipline, identifying the focus of research and the national and international strengths and biases $[4,5]$. Over the course of the past few decades, several bibliometric analyses have been published regarding diverse topics in the literature of health research, including medicine and international health, where studies have tried to evaluate the contribution of different world regions in research production in infection diseases in terms of both quantity and quality [6], in respiratory research productivity where countries from Western Europe, Canada and Oceania had the best performance after adjustment for population and gross national income per capita [7], in cardiovascular research production where the results showed a promising trend of research productivity for developing world regions with the exception of Africa [8], and also look at the bibliometric profile of tropical medicine and international health [9]. In health informatics studies have included an up-to-date view of the telemedicine and telehealth literature analyzing the changes in content themes [10], assessing the impact of grants in the contribution to scientific knowledge of health information technologies on patient safety and quality of care outcomes [11], quantifying the number of publications on electronic health records and their changes over time [12], and studying the contribution of individual countries to leading journals in medical informatics [13]. Among occupational health, articles have helped to identify the most pertinent journals in the practice of occupational health and to develop search strategies that facilitate finding occupational health intervention studies [14-16]. There are also bibliometric analysis published in health management that investigate the attention and progress of strategic management in the literature [17], in health economics, studies have reported the growth of health economics literature and the change in topics and geographical focus of health economics [18-20]. Bibliometric studies in health service research have looked for trends, gaps and characteristics when comparing among different regions [21, 22], in the same line other studies have assessed the scientific production in health policy $[23,24]$, in primary health $[25,26]$, in epidemiology $[27,28]$, in environmental health [29-31], in public health and preventive medicine [32, 33], in preventive medicine, occupational and environmental medicine, epidemiology, and public health [34], and also public in health research in specific countries or regions [35-42]. This literature has become relevant today perhaps due to the diverse disciplines that are engaged in health research and its importance in order to monitor and disseminate the scientific achievements from the research work.

In this current study we aim to expand the scope of analysis of health research even more, identifying and quantifying the scholarly publications in the field and subfield approaches of public health, environmental and occupational health, health management and economics, health promotion and health behavior, epidemiology, health policy and services, medicine, health informatics, engineering and technology and primary care. Our main goal is to produce an overview of the leading journals in health research literature in the world for a time frame of 25 years from 1990 to 2014. There are many aspects that can indicate the value of a journal; in this study we use the number of citations and their impact factor to reflect the quality of the review process and its popularity in the scientific community. Findings from this research may assist researchers to identify top performance journals in a subject area, learn more about the subfields of health research, and identify emerging areas of research to locate areas of potential study.

\section{Methods}

There are different approaches for classifying the bibliographic material. Bibliometrics is one of the most common approaches [43, 44]. In order to represent the results, the analysis uses a wide range of indicators that measure the quality of the publications. Currently, there is no general agreement on the optimal method for measuring research because depending on the perspective considered an indicator may be better than another one. Therefore, the current literature deals with many indicators that have appeared during the last years [45-47]. 
Table 1 Most influential journals in Public Health Research

\begin{tabular}{|c|c|c|c|c|c|c|c|c|c|c|c|c|c|c|}
\hline $\mathrm{R}$ & Journal name & TC & TP & $\mathrm{H}$ & TC/TP & Year & Volume & IF & IF5 & $\mathrm{T} 50$ & T200 & T200* & GR & $\begin{array}{l}\text { First } \\
\text { year }\end{array}$ \\
\hline 1 & American Journal of Public Health & 302196 & 9203 & 198 & 32,84 & 1991 & 81 & 4,229 & 4,997 & 15 & 9 & 1 & 3 & 1911 \\
\hline 2 & Social Science \& Medicine & 281663 & 9656 & 163 & 29,17 & 1990 & 31 & 2,558 & 3,568 & 17 & 14 & 0 & 4 & 1967 \\
\hline 3 & Bulletin of The World Health Organization & 80812 & 2597 & 110 & 31,12 & 1990 & 68 & 5,112 & 6,372 & 8 & 7 & 14 & 22 & 1948 \\
\hline 4 & BMC Public Health & 60880 & 7434 & 64 & 8,19 & 2001 & 1 & 2,321 & 2,781 & 0 & 0 & 0 & 31 & 2001 \\
\hline 5 & Public Health Nutrition & 46882 & 2988 & 84 & 15,69 & 1999 & 2 & 2,483 & 2,798 & 1 & 1 & 0 & 41 & 1998 \\
\hline 6 & Drug Safety & 46562 & 2005 & 87 & 23,22 & 1990 & 5 & 2,620 & 3,424 & 0 & 0 & 0 & 42 & 1986 \\
\hline 7 & Annual Review of Public Health & 39592 & 595 & 104 & 66,54 & 1991 & 12 & 6,627 & 7,984 & 4 & 4 & 1 & 51 & 1980 \\
\hline 8 & Public Health Reports & 34617 & 2064 & 67 & 13,29 & 1990 & 105 & 1,644 & 1,791 & 1 & 1 & 2 & 61 & 2001 \\
\hline 9 & Australian and New Zealand Journal of Public Health & 22531 & 2219 & 54 & 10,15 & 1996 & 20 & 1,897 & 1,835 & 0 & 0 & 0 & 82 & 1977 \\
\hline 10 & $\begin{array}{l}\text { Canadian Journal of Public Health-Revue Canadienne } \\
\text { de Sante Publique }\end{array}$ & 20835 & 2515 & 44 & 8,28 & 1990 & 81 & 1,094 & 1,325 & 1 & 1 & 0 & 88 & 1997 \\
\hline 11 & European Journal of Public Health & 20399 & 1851 & 51 & 11,02 & 1997 & 7 & 2,459 & 2,743 & 0 & 0 & 0 & 91 & 1991 \\
\hline 12 & Public Health & 20393 & 2488 & 48 & 8,2 & 1990 & 104 & 1,475 & 1,514 & 0 & 0 & 0 & 92 & 1888 \\
\hline 13 & Revista de Saude Publica & 18366 & 2810 & 41 & 6,54 & 1990 & 24 & 1,219 & 1,587 & 0 & 0 & 0 & 97 & 1967 \\
\hline 14 & Scandinavian Journal of Public Health & 17440 & 1568 & 50 & 11,12 & 1999 & 27 & 3,125 & 2,570 & 0 & 0 & 0 & 103 & 1973 \\
\hline 15 & Journal of American College Health & 15664 & 1011 & 57 & 15,49 & 1994 & 43 & 1,397 & 2,223 & 2 & 1 & 0 & 109 & 1978 \\
\hline 16 & Journal of Safety Research & 13917 & 1070 & 47 & 13,01 & 1990 & 21 & 1,303 & 1,940 & 0 & 0 & 0 & 116 & 1982 \\
\hline 17 & Public Health Nursing & 11167 & 1373 & 37 & 8,13 & 1990 & 7 & 0,886 & 1,131 & 0 & 0 & 0 & 137 & 1984 \\
\hline 18 & Maternal and Child Health Journal & 9992 & 1434 & 36 & 6,97 & 2004 & 8 & 2,015 & 2,318 & 0 & 0 & 0 & 143 & 1997 \\
\hline 19 & Salud Publica de Mexico & 8805 & 2008 & 30 & 4,38 & 1993 & 35 & 1,034 & 1,221 & 0 & 0 & 0 & 154 & 1997 \\
\hline 20 & Ethnicity \& Disease & 7952 & 1285 & 32 & 6,19 & 2004 & 14 & 0,921 & 1,233 & 0 & 0 & 0 & 160 & 2003 \\
\hline
\end{tabular}

Abbreviations: TC Total citations, TP Total papers, $H$ Hirsch index, TC/TP Average citations per paper, IF Impact factor, IF5 5-year impact factor, T50 Number of papers among the 50 most cited of the category, T200 and T200* Number of papers among the 200 most cited in all fields of health between 1990-2014 and before 1990, GR Global ranking considering all the journals

In this study, the aim is to provide a general picture in order to get a complete overview that can adapt to the interests and perspectives of each specific reader. Thus, several indicators are considered including the total number of publications and citations, the citations per paper, the $h$ index [48] and the number of papers that a journal has among the most cited ones in a specific field. Note that the most cited papers are found in Web of Science (WoS) by ordering the results of a search from the most cited papers to the less cited [49].

The study uses the WoS database in order to search for the information. WoS is usually regarded as the most influential database for scientific research because it includes those journals that are generally recognized with the highest quality. It was originally created by Eugene Garfield with the name of Institute for Scientific Information (ISI). Later, Thomson \& Reuters bought the ISI, renaming it ISI Web of Knowledge and later WoS. Note that other databases are available and could also be used in the analysis including Scopus and Google Scholar. Scientific research is divided in 251 categories in WoS. Four of them involve health research: Public, Environmental \& Occupational Health, Health Policy \& Services, Health Care Sciences \& Services, and Primary Health Care. Note that the first one appears both in the Science Citation Index and in the Social Science Citation Index. These four categories encompass 363 journals. Since these four categories are very broad, the study divides health research in nine categories in order to get a deeper picture of the leading journals in each subfield. However, it is worth noting that sometimes it was not clear where to classify a journal because its scope may include two or three subfields. In any case, the analysis considers a Global Ranking (GR) where all the journals are ranked together. This allows comparison between subfields when needed. The nine categories are:

- Public Health

- Environmental and Occupational Health

- Health Management and Economics

- Health Promotion and Health Behavior

- Epidemiology

- Health Policy and Services

- Medicine

- Health Informatics, Engineering and Technology

- Primary Care

Although the work considers many indicators, the ranking is carried out according to the total number of 
Table 2 Most influential journals in Environmental and Occupational Health Research

\begin{tabular}{|c|c|c|c|c|c|c|c|c|c|c|c|c|c|c|}
\hline $\mathrm{R}$ & Journal name & TC & TP & $\mathrm{H}$ & $\mathrm{TC} / \mathrm{TP}$ & Year & Volume & $\mathrm{IF}$ & IF5 & T50 & T200 & T200* & GR & $\begin{array}{l}\text { First } \\
\text { year }\end{array}$ \\
\hline 1 & Environmental Health Perspectives & 311509 & 8066 & 192 & 38,62 & 1990 & 89 & 7,029 & 7,607 & 40 & 22 & 3 & 2 & 1972 \\
\hline 2 & Occupational and Environmental Medicine & 71955 & 3211 & 98 & 22,41 & 1994 & 51 & 3,234 & 3,466 & 0 & 0 & 1 & 26 & 1944 \\
\hline 3 & American Journal of Industrial Medicine & 62605 & 3745 & 76 & 16,72 & 1990 & 18 & 1,590 & 1,899 & 1 & 1 & 1 & 29 & 1980 \\
\hline 4 & Environmental Research & 62104 & 2695 & 91 & 23,04 & 1990 & 53 & 3,951 & 4,033 & 1 & 0 & 0 & 30 & 1967 \\
\hline 5 & Accident Analysis and Prevention & 60584 & 3760 & 83 & 16,11 & 1990 & 22 & 2,571 & 3,096 & 0 & 0 & 0 & 32 & 1969 \\
\hline 6 & Journal of Occupational and Environmental Medicine & 57259 & 4235 & 80 & 13,52 & 1990 & 32 & 1,797 & 2,09 & 0 & 0 & 1 & 34 & 1959 \\
\hline 7 & Radiation Protection Dosimetry & 53396 & 9063 & 55 & 5,89 & 1990 & 30 & 0,861 & 0,981 & 0 & 0 & 0 & 36 & 1981 \\
\hline 8 & Scandinavian Journal of Work Environment \& Health & 44939 & 1853 & 83 & 24,25 & 1990 & 16 & 3,095 & 3,869 & 3 & 1 & 0 & 45 & 1975 \\
\hline 9 & $\begin{array}{l}\text { International Archives of Occupational and } \\
\text { Environmental Health }\end{array}$ & 37358 & 2381 & 66 & 15,69 & 1990 & 62 & 2,198 & 2,199 & 1 & 1 & 0 & 56 & 1930 \\
\hline 10 & Aviation Space and Environmental Medicine & 34588 & 4265 & 51 & 8,11 & 1990 & 61 & 0,782 & 0,998 & 0 & 0 & 0 & 62 & 1930 \\
\hline 11 & Annals of Occupational Hygiene & 22748 & 1844 & 52 & 12,34 & 1990 & 34 & 2,068 & 2,148 & 0 & 0 & 0 & 79 & 1958 \\
\hline 12 & Indoor Air & 20871 & 948 & 62 & 22,02 & 1994 & 4 & 4,904 & - & 0 & 0 & 0 & 87 & 1991 \\
\hline 13 & Health \& Place & 19584 & 1384 & 58 & 14,15 & 1995 & 1 & 2,435 & 3,003 & 0 & 0 & 0 & 95 & 1995 \\
\hline 14 & Occupational Medicine-Oxford & 19400 & 2080 & 53 & 9,33 & 1992 & 42 & 1,472 & 1,682 & 1 & 0 & 0 & 96 & 1948 \\
\hline 15 & $\begin{array}{l}\text { Journal of Toxicology and Environmental Health-Part } \\
\text { A-Current Issues }\end{array}$ & 17092 & 1670 & 44 & 10,23 & 1998 & 53 & 1,834 & 1,868 & 0 & 0 & 0 & 104 & 1975 \\
\hline 16 & $\begin{array}{l}\text { International Journal of Hygiene and Environmental } \\
\text { Health }\end{array}$ & 15445 & 1080 & 51 & 14,3 & 2000 & 203 & 3,276 & 3,331 & 0 & 0 & 0 & 110 & 2000 \\
\hline 17 & Toxicology and Industrial Health & 15004 & 1429 & 49 & 10,5 & 1990 & 6 & 1,710 & 1,591 & 3 & 0 & 0 & 115 & 1985 \\
\hline 18 & $\begin{array}{l}\text { Journal of Environmental Science and Health Part B- } \\
\text { Pesticides Food Contaminants and Agricultural Wastes }\end{array}$ & 13210 & 1901 & 34 & 6,95 & 1990 & 25 & 1,234 & 1,129 & 0 & 0 & 0 & 122 & 1976 \\
\hline 19 & Environmental Geochemistry and Health & 12095 & 1093 & 42 & 11,07 & 1990 & 12 & 2,573 & 2,534 & 0 & 0 & 0 & 128 & 1979 \\
\hline 20 & Industrial Health & 10652 & 1444 & 35 & 7,38 & 1990 & 28 & 1,045 & 1,132 & 0 & 0 & 0 & 140 & 1963 \\
\hline
\end{tabular}

Abbreviations: TC Total citations, TP Total papers, $H$ Hirsch index, TC/TP Average citations per paper, IF Impact factor, IF5 5-year impact factor, T50 Number of papers among the 50 most cited of the category, T200 and T200* Number of papers among the 200 most cited in all fields of health between $1990-2014$ and before $1990, G R$ Global ranking considering all the journals

citations. The main reason for this is that the citations measure the influence that a journal has in absolute terms. Other alternatives could be considered including the citations per paper and the $h$-index. The main limitation of this indicator is that it does not take into account the number of papers that have generated the number of cites. However, the rest of indicators included in the tables allow the reader to get a comprehensive overview of each journal although the ranking is focused on the number of citations.

The analysis focuses on the last 25 years (1990-2014). The main reason is because this time period is representative of the latest developments of the field. In order to take into account the influence from a classical perspective, the study includes an indicator that shows the number of articles that a journal has among the 200 most cited articles published before 200. This allows the reader to see those journals that were very influential before and see if they are still leading the field or not. Note that the search process carried out in WoS has been developed between March and
August 2015. The types of documents considered are: articles, reviews, notes and letters.

\section{Results}

This section presents the main bibliometric results found in WoS for 363 health research journals from 1990 to 2014. The results are ordered by category and each table contains the 20 or 10 most cited journals of each category (see the Additional file 1 for the full list of journals).

\section{Public health}

Public health refers to the activities to prevent diseases, promote health, and prolong life for the whole population [50]. Therefore, the main objective of public health is assuring conditions for the people in order to be healthy. It is at the core of health research and consequently there are many journals devoted to increase knowledge and raise awareness on this topic. Table 1 shows the most influential journals among this category. 
Table 3 Most influential journals in Health Management and Economics Research

\begin{tabular}{|c|c|c|c|c|c|c|c|c|c|c|c|c|c|c|}
\hline $\mathrm{R}$ & Journal name & TC & TP & $\mathrm{H}$ & TC/TP & Year & Volume & IF & IF5 & $\mathrm{T} 50$ & T200 & T200* & GR & $\begin{array}{l}\text { First } \\
\text { year }\end{array}$ \\
\hline 1 & Medical Care & 162015 & 3890 & 145 & 41,65 & 1990 & 28 & 2,941 & 3,714 & 31 & 16 & 10 & 9 & 1963 \\
\hline 2 & Risk Analysis & 50164 & 2716 & 85 & 18,47 & 1990 & 10 & 1,974 & 2,546 & 5 & 2 & 1 & 38 & 1981 \\
\hline 3 & Journal of Health Economics & 39818 & 1400 & 85 & 28,44 & 1990 & 9 & 2,254 & 3,159 & 5 & 3 & 1 & 49 & 1982 \\
\hline 4 & Pharmacoeconomics & 37078 & 2163 & 69 & 17,04 & 1993 & 4 & 3,338 & 3,509 & 2 & 0 & 0 & 57 & 1992 \\
\hline 5 & Medical Decision Making & 34695 & 1511 & 80 & 22,96 & 1990 & 10 & 2,698 & 3,083 & 5 & 1 & 1 & 59 & 1981 \\
\hline 6 & Health Economics & 32797 & 1643 & 72 & 19,96 & 1994 & 3 & 2,137 & 2,570 & 2 & 0 & 0 & 65 & 1992 \\
\hline 7 & BMC Health Services Research & 25343 & 3474 & 49 & 7,3 & 2001 & 1 & 1,659 & 2,188 & 0 & 0 & 0 & 72 & 2001 \\
\hline 8 & American Journal of Managed Care & 24099 & 2483 & 57 & 9,71 & 1997 & 3 & 2,166 & 2,688 & 0 & 0 & 0 & 76 & 1995 \\
\hline 9 & $\begin{array}{l}\text { Inquiry-The Journal of Health Care Organization } \\
\text { Provision and Financing }\end{array}$ & 9704 & 711 & 43 & 13,65 & 1990 & 97 & 0,564 & 0,793 & 0 & 0 & 0 & 146 & 1964 \\
\hline 10 & Health Care Management Review & 6392 & 702 & 32 & 9,11 & 1994 & 19 & 1,642 & 2,071 & 0 & 0 & 0 & 179 & 1976 \\
\hline 11 & American Journal of Medical Quality & 5264 & 698 & 30 & 7,5 & 1999 & 14 & 1,776 & 1,821 & 0 & 0 & 0 & 189 & 1986 \\
\hline 12 & Journal of Managed Care Pharmacy & 4630 & 616 & 31 & 7,52 & 2006 & 12 & 2,682 & 2,858 & 0 & 0 & 0 & 198 & 1995 \\
\hline 13 & Journal of Public Health Management and Practice & 3661 & 865 & 21 & 4,23 & 2005 & 11 & 0,84 & 1,198 & 0 & 0 & 0 & 211 & 1995 \\
\hline 14 & $\begin{array}{l}\text { International Journal of Health Planning and } \\
\text { Management }\end{array}$ & 3470 & 512 & 26 & 6,78 & 1994 & 9 & 0,971 & 1,029 & 0 & 0 & 0 & 213 & 1985 \\
\hline 15 & Economics \& Human Biology & 3326 & 348 & 29 & 9,56 & 2006 & 4 & 2,461 & 2,878 & 0 & 0 & 0 & 217 & 2003 \\
\hline 16 & Journal of Healthcare Management & 2919 & 514 & 24 & 5,68 & 1998 & 43 & 0,96 & 0,977 & 0 & 0 & 0 & 224 & 2007 \\
\hline 17 & European Journal of Health Economics & 2403 & 495 & 19 & 4,85 & 2007 & 8 & 1,913 & 1,865 & 0 & 0 & 0 & 230 & 2000 \\
\hline 18 & Australian Health Review & 2098 & 669 & 17 & 3,14 & 2007 & 31 & 1,000 & 1,127 & 0 & 0 & 0 & 236 & 1978 \\
\hline 19 & Human Resources for Health & 2048 & 371 & 20 & 5,52 & 2008 & 6 & 1,922 & 2,392 & 0 & 0 & 0 & 237 & 2003 \\
\hline 20 & International Journal for Equity in Health & 1761 & 458 & 16 & 3,84 & 2008 & 7 & 1,589 & 1,925 & 0 & 0 & 0 & 247 & 2002 \\
\hline
\end{tabular}

Abbreviations: TC Total citations, TP Total papers, $H$ Hirsch index, TC/TP Average citations per paper, IF Impact factor, IF5 5-year impact factor, T50 Number of papers among the 50 most cited of the category, T200 and T200* Number of papers among the 200 most cited in all fields of health between 1990-2014 and before 1990, GR Global ranking considering all the journals

The journal that has received more citations and the higher h-index in this field is the American Journal of Public Health with 302,196 citations and an $h$-index of 198; followed by Social Science \& Medicine with 281,663 citations and an $h$-index of 163 . These two journals dominate the number of citations in the field with more than $50 \%$ of all the cites. Despite these elevated numbers, the highest average citation rate per paper, impact factor, and 5-year impact factor is for the Annual Review of Public Health.

Analyzing the T50 and T200 ranking results, Social Science \& Medicine is in the top positions with 17 papers or $34 \%$ of the papers in the T50 ranking of the category, followed by the American Journal of Public Health with $30 \%$ of the papers in the T50. The same journals have 9 and 14 papers respectively in the T200 ranking. Note that all the journals of the category have an $h$-index bigger than 20 , reflecting its influence and productivity.

\section{Environmental and occupational health}

Environmental health studies the impact of our surroundings in health, while occupational health studies all aspects of health and safety in the workplace. This category includes journals regarding the understanding of the impact and control of environmental and occupational hazards on human health and society. Table 2 presents the results for this category.

The journal Environmental Health Perspectives has the highest results in all the measures, with 311,509 citations that are far from any other journal in the category, an $h$-index of 192, and an impact factor of 7.029. It has also $80 \%$ of the papers in the T50 ranking, and 22 papers in the T200 ranking of the most cited papers in all fields of health.

\section{Health management and economics}

This category includes journals related to the economics and management of health and healthcare (see Table 3).

Medical Care is the journal positioned number one in this category according to the number of citations, $h$ index, average citations per paper, and 5-year impact factor. It has $62 \%$ of the papers among the 50 most cited in the category, and 16 out of the 200 most cited in all fields of health. However, the highest impact factor in the category is for Pharmaeconomics, positioned fourth according to the total number of citations. 


\section{Health promotion and health behavior}

Health promotion and health behavior refers to the role of behavioral and social influences to address current and emerging public health problems. Table 4 shows the most influential journals in this category.

As we can see in Table 4, there are two journals leading the citation ranking: the American Journal of Preventive Medicine and Preventive Medicine with 115,942 and 111,066 citations respectively. Also these two journals have an $h$-index over 100 . The Tobacco Control Journal has the highest impact factor of 5150; however, the American Journal of Preventive Medicine has the highest 5-year impact factor. Additionally, the American Journal of Preventive Medicine has 13 studies in the T50 ranking and five in the T200.

\section{Epidemiology}

Epidemiology is a basic science of public health. It studies the distributions and determinants of health problems in different groups of people. Epidemiological information is used to plan and evaluate strategies to control or prevent diseases. Table 5 presents the main journals in this category.
The American Journal of Epidemiology is in the first place of this category, and also among all the categories according to the global ranking (GR). It has also the highest $h$-index of all categories, reflecting his influence and impact. It is followed by the Cancer Epidemiology Biomarkers \& Prevention and the Journal of Clinical Epidemiology that occupy positions 5 and 7 in the GR. The highest impact factor and 5-year impact factor is for the Epidemiology journal with values of 6178 and 6894 respectively. Regarding the T50 ranking, the Journal of Clinical Epidemiology has $46 \%$ of the most cited papers in this category and the American Journal of Epidemiology has $22 \%$. In the T200 ranking, this category has 39 out of the 200 most cited journals in all the fields, eight are from the American Journal of Epidemiology and 16 of the Journal of Clinical Epidemiology.

\section{Health policy and services}

This category includes journals from multidisciplinary fields of scientific investigation that study among others the rising demand for health services, how to improve their quality and efficiency, and rigorous policy analysis that ultimately impact our health and well-being (see Table 6).

Table 4 Most influential journals in Health Promotion and Health Behavior

\begin{tabular}{|c|c|c|c|c|c|c|c|c|c|c|c|c|c|c|}
\hline $\mathrm{R}$ & Journal name & TC & TP & $\mathrm{H}$ & $\mathrm{TC} / \mathrm{TP}$ & Year & Volume & IF & IF5 & T50 & T200 & T200* & GR & $\begin{array}{l}\text { First } \\
\text { year }\end{array}$ \\
\hline 1 & American Journal of Preventive Medicine & 115942 & 3947 & 133 & 29,37 & 1990 & 6 & 4,281 & 5,092 & 13 & 5 & 5 & 12 & 1985 \\
\hline 2 & Preventive Medicine & 111066 & 4186 & 122 & 26,53 & 1990 & 19 & 2,932 & 3,917 & 4 & 3 & 3 & 14 & 1972 \\
\hline 3 & Journal of Adolescent Health & 78449 & 3676 & 96 & 21,34 & 1990 & 11 & 2,748 & 3,753 & 2 & 0 & 0 & 23 & 1980 \\
\hline 4 & Patient Education and Counseling & 59813 & 3611 & 83 & 16,56 & 1990 & 15 & 2,598 & 3,158 & 2 & 0 & 0 & 33 & 1978 \\
\hline 5 & Medical Education & 50964 & 3253 & 79 & 15,67 & 1990 & 24 & 3,617 & 3,963 & 0 & 0 & 0 & 37 & 1966 \\
\hline 6 & Journal of Health and Social Behavior & 45820 & 728 & 107 & 62,94 & 1990 & 31 & 2,951 & 4,457 & 8 & 4 & 4 & 44 & 1960 \\
\hline 7 & Supportive Care in Cancer & 39781 & 3384 & 62 & 11,76 & 1993 & 1 & 2,495 & 2,845 & 0 & 0 & 0 & 50 & 1993 \\
\hline 8 & $\begin{array}{l}\text { AIDS Care-Psychological and Socio-Medical Aspects } \\
\text { of AIDS/HIV }\end{array}$ & 39017 & 2795 & 66 & 13,96 & 1992 & 4 & 2,194 & 2,454 & 1 & 1 & 1 & 53 & 1989 \\
\hline 9 & American Journal of Community Psychology & 33534 & 1259 & 84 & 26,64 & 1990 & 18 & 1,968 & 2,888 & 1 & 1 & 0 & 63 & 1973 \\
\hline 10 & Tobacco Control & 32078 & 1641 & 74 & 19,55 & 1998 & 7 & 5,150 & 4,532 & 1 & 0 & 0 & 66 & 1992 \\
\hline 11 & Health Education Research & 31136 & 1594 & 73 & 19,53 & 1991 & 6 & 1,944 & 2,508 & 0 & 0 & 0 & 67 & 1986 \\
\hline 12 & Qualitative Health Research & 28115 & 1864 & 58 & 15,08 & 1995 & 5 & 1,441 & - & 1 & 1 & 0 & 70 & 1991 \\
\hline 13 & Psychology \& Health & 24761 & 1407 & 57 & 17,6 & 1992 & 7 & 2,255 & 2,107 & 5 & 1 & 1 & 74 & 1987 \\
\hline 14 & Medical Teacher & 24402 & 3370 & 52 & 7,24 & 1990 & 12 & 2,045 & 2,170 & 1 & 1 & 1 & 75 & 1979 \\
\hline 15 & Sociology of Health \& IIIness & 23121 & 1134 & 65 & 20,39 & 1990 & 12 & 2,014 & 2,62 & 0 & 0 & 0 & 77 & 1979 \\
\hline 16 & AIDS and Behavior & 22636 & 1863 & 55 & 12,15 & 2003 & 7 & 3,312 & 3,977 & 0 & 0 & 0 & 81 & 1997 \\
\hline 17 & American Journal of Health Promotion & 21372 & 1072 & 63 & 19,94 & 1995 & 9 & 1,762 & 2,389 & 4 & 2 & 2 & 83 & 1986 \\
\hline 18 & AIDS Education and Prevention & 20901 & 1123 & 57 & 18,61 & 1992 & 4 & 1,505 & 2,298 & 0 & 0 & 0 & 86 & 1989 \\
\hline 19 & Journal of School Health & 20436 & 1887 & 56 & 10,83 & 1990 & 60 & 1,659 & 2,132 & 0 & 0 & 0 & 90 & 1930 \\
\hline 20 & AIDS Patient Care and STDs & 20210 & 1622 & 49 & 12,46 & 1996 & 10 & 3,576 & 3,255 & 0 & 0 & 0 & 93 & 1987 \\
\hline
\end{tabular}

Abbreviations: TC Total citations, TP Total papers, $H$ Hirsch index, TC/TP Average citations per paper, IF Impact factor, IF5 5-year impact factor, T50 Number of papers among the 50 most cited of the category, T200 and T200* Number of papers among the 200 most cited in all fields of health between 1990-2014 and before 1990, GR Global ranking considering all the journals 
Table 5 Most influential journals in Epidemiology

\begin{tabular}{|c|c|c|c|c|c|c|c|c|c|c|c|c|c|c|}
\hline $\mathrm{R}$ & Journal name & TC & TP & $\mathrm{H}$ & $\mathrm{TC} / \mathrm{TP}$ & Year & Volume & IF & IF5 & $\mathrm{T} 50$ & T200 & T200* & GR & $\begin{array}{l}\text { First } \\
\text { year }\end{array}$ \\
\hline 1 & American Journal of Epidemiology & 357243 & 8162 & 211 & 43,77 & 1990 & 131 & 4,975 & 6,067 & 11 & 8 & 49 & 1 & 1921 \\
\hline 2 & Cancer Epidemiology Biomarkers \& Prevention & 207614 & 6073 & 147 & 34,19 & 1991 & 1 & 4,324 & 4,647 & 2 & 1 & 0 & 5 & 1991 \\
\hline 3 & Journal of Clinical Epidemiology & 168450 & 4502 & 167 & 37,42 & 1990 & 43 & 5,478 & 5,898 & 17 & 16 & 2 & 7 & 1955 \\
\hline 4 & Statistics in Medicine & 148692 & 6505 & 140 & 22,86 & 1990 & 9 & 2,037 & 2,828 & 0 & 0 & 6 & 10 & 1982 \\
\hline 5 & International Journal of Epidemiology & 140691 & 4335 & 134 & 32,45 & 1990 & 19 & 9,197 & 8,000 & 3 & 0 & 3 & 11 & 1972 \\
\hline 6 & Journal of Epidemiology and Community Health & 99343 & 3939 & 117 & 25,22 & 1990 & 44 & 3,294 & 3,667 & 2 & 2 & 3 & 15 & 1947 \\
\hline 7 & Epidemiology & 93837 & 3124 & 126 & 30,04 & 1991 & 2 & 6,178 & 6,894 & 1 & 1 & 0 & 16 & 1990 \\
\hline 8 & Infection Control and Hospital Epidemiology & 86969 & 4588 & 100 & 18,96 & 1990 & 11 & 3,938 & 4,423 & 5 & 3 & 0 & 18 & 1980 \\
\hline 9 & Cancer Causes \& Control & 83834 & 3003 & 112 & 27,92 & 1990 & 1 & 2,961 & 3,434 & 1 & 1 & 0 & 21 & 1990 \\
\hline 10 & Epidemiology and Infection & 73121 & 4117 & 85 & 17,76 & 1990 & 104 & 2,491 & 2,671 & 0 & 0 & 0 & 25 & 1901 \\
\hline 11 & European Journal of Epidemiology & 46372 & 2896 & 71 & 16,01 & 1990 & 6 & 5,147 & 4,245 & 1 & 1 & 0 & 43 & 1985 \\
\hline 12 & Annals of Epidemiology & 43089 & 2002 & 83 & 21,52 & 1996 & 6 & 2,145 & 2,895 & 0 & 0 & 0 & 48 & 1990 \\
\hline 13 & Genetic Epidemiology & 38300 & 2040 & 77 & 18,77 & 1990 & 7 & 2,951 & 3,489 & 1 & 1 & 1 & 54 & 1984 \\
\hline 14 & Epidemiologic Reviews & 34630 & 456 & 93 & 75,94 & 1990 & 12 & 7,333 & 12,344 & 4 & 3 & 5 & 60 & 1979 \\
\hline 15 & Community Dentistry and Oral Epidemiology & 33089 & 1726 & 66 & 19,17 & 1990 & 18 & 1,944 & 2,491 & 0 & 0 & 0 & 64 & 1973 \\
\hline 16 & Neuroepidemiology & 24773 & 1314 & 62 & 18,85 & 1990 & 9 & 2,476 & 2,863 & 0 & 0 & 0 & 73 & 1982 \\
\hline 17 & Paediatric and Perinatal Epidemiology & 21249 & 1228 & 59 & 17,3 & 1994 & 8 & 2,811 & 2,796 & 0 & 0 & 0 & 84 & 1987 \\
\hline 18 & $\begin{array}{l}\text { Journal of Urban Health-Bulletin of the New York } \\
\text { Academy of Medicine }\end{array}$ & 18231 & 1274 & 54 & 14,31 & 1998 & 75 & 1,943 & 2,517 & 0 & 0 & 0 & 99 & 1925 \\
\hline 19 & Statistical Methods in Medical Research & 11801 & 490 & 44 & 24,08 & 1999 & 8 & 2,957 & 3,155 & 2 & 2 & 0 & 131 & 1992 \\
\hline 20 & BMC Medical Research Methodology & 8936 & 979 & 39 & 9,13 & 2007 & 7 & 2,168 & 3,024 & 0 & 0 & 0 & 153 & 2001 \\
\hline
\end{tabular}

Abbreviations: TC Total citations, TP Total papers, $H$ Hirsch index, TC/TP Average citations per paper, IF Impact factor, IF5 5-year impact factor, T50 Number of papers among the 50 most cited of the category, T200 and T200* Number of papers among the 200 most cited in all fields of health between 1990-2014 and before 1990, GR Global ranking considering all the journals

Even though Health Affairs is the most cited journal, the Milbank Quarterly has the highest TC/TP ratio, impact factor, and 5-year impact factor, being the most influential in the category. It is also worthiest to notice that Quality of Life Research has 15 out of the 50 most influential papers in the category, followed by Health Affairs with 11 and Milbank Quarterly with eight. Quality of Life Research and Milbank Quarterly have three papers each in the T200 ranking.

\section{Medicine}

Medicine is one of the world's oldest categories in the arena of health research, allowing scientists and physicians to communicate their advances. The results of this category are displayed in Table 7.

American Journal of Tropical Medicine and Hygiene is the most influential according to its total number of citations of 178,865 . However, the h-index is the same for the American Journal of Tropical Medicine and Hygiene and the Journal of General Internal Medicine, but the $\mathrm{TC} / \mathrm{TP}$ ratio and impact factor is higher for the latter. The highest impact factor and 5-year impact factor is for the Implementation Science journal. In the T50 ranking, Academic Medicine appears with 12 papers, the
American Journal of Tropical Medicine and Hygiene with 9, and the Journal of General Internal Medicine has 14 in this ranking and three in the T200 ranking.

\section{Health informatics, engineering and technology}

This category involves the research and integration of resources, devices, and methodologies to optimize the use of information to provide a better healthcare. The Top ten journals in this category are shown in Table 8.

The Journal of the American Medical Informatics Association is the most influential in this category with the highest number of citations, $h$-index, TC/TP ranking, impact factor, 5-year impact factor. Additionally, it has $52 \%$ of the papers among the 50 most cited of the category, but none in the T200. Health Physics and Health Technology Assessment have one paper each in the T200 ranking.

\section{Primary care}

Primary care is all the regular health services and social services that are available for the population, and its research is at the cornerstone for building a strong healthcare system. Table 9 presents the Top ten journals in this category. 
Table 6 Most influential journals in Health Policy and Services

\begin{tabular}{|c|c|c|c|c|c|c|c|c|c|c|c|c|c|c|}
\hline $\mathrm{R}$ & Journal name & $\mathrm{TC}$ & TP & $\mathrm{H}$ & $\mathrm{TC} / \mathrm{TP}$ & Year & Volume & IF & IF5 & $\mathrm{T} 50$ & T200 & T200* & GR & $\begin{array}{l}\text { First } \\
\text { year }\end{array}$ \\
\hline 1 & Health Affairs & 85858 & 5495 & 106 & 15,62 & 1990 & 9 & 4,321 & 4,402 & 11 & 1 & 1 & 19 & 1981 \\
\hline 2 & Quality of Life Research & 65856 & 2697 & 102 & 24,42 & 1993 & 2 & 2,864 & 3,270 & 15 & 3 & 3 & 28 & 1992 \\
\hline 3 & Health Services Research & 44904 & 1997 & 82 & 22,49 & 1990 & 24 & 2,491 & 2,772 & 4 & 0 & 0 & 46 & 1967 \\
\hline 4 & Health Policy & 29530 & 1646 & 53 & 11,16 & 1990 & 14 & 1,725 & 1,923 & 1 & 1 & 1 & 68 & 1980 \\
\hline 5 & Milbank Quarterly & 22965 & 605 & 69 & 37,96 & 1990 & 68 & 5,391 & 6,513 & 8 & 3 & 3 & 78 & 1923 \\
\hline 6 & Health Policy and Planning & 20646 & 1306 & 56 & 15,81 & 1991 & 6 & 3,442 & 3,703 & 1 & 0 & 0 & 89 & 1986 \\
\hline 7 & International Journal for Quality in Health Care & 18340 & 1299 & 54 & 14,12 & 1995 & 7 & 1,584 & 2,296 & 1 & 0 & 0 & 98 & 1989 \\
\hline 8 & Value in Health & 18129 & 1403 & 53 & 12,92 & 2002 & 5 & 2,891 & 3,174 & 3 & 0 & 0 & 100 & 1998 \\
\hline 9 & Community Mental Health Journal & 15045 & 1391 & 49 & 10,82 & 1990 & 26 & 1,146 & 1,422 & 0 & 0 & 0 & 113 & 1965 \\
\hline 10 & Medical Care Research and Review & 13328 & 636 & 55 & 20,96 & 1995 & 52 & 2,600 & 3,638 & 2 & 0 & 0 & 119 & 1944 \\
\hline 11 & Hastings Center Report & 11744 & 2179 & 47 & 5,39 & 1990 & 20 & 1,080 & 1,131 & 0 & 0 & 0 & 132 & 1971 \\
\hline 12 & International Journal of Health Services & 11664 & 1102 & 46 & 10,58 & 1990 & 20 & 0,988 & 1,236 & 2 & 0 & 0 & 133 & 1971 \\
\hline 13 & Health and Quality of Life Outcomes & 11595 & 1199 & 44 & 9,67 & 2006 & 4 & 2,099 & 3,152 & 0 & 0 & 0 & 135 & 2003 \\
\hline 14 & Journal of Aging and Health & 11313 & 857 & 45 & 13,2 & 1995 & 7 & 1,832 & 2,057 & 0 & 0 & 0 & 136 & 1989 \\
\hline 15 & Journal of Health Politics Policy and Law & 10243 & 1023 & 41 & 10,01 & 1990 & 15 & 0,962 & 1,169 & 0 & 0 & 0 & 141 & 1976 \\
\hline 16 & $\begin{array}{l}\text { Journal of Health Care for the Poor and } \\
\text { Underserved }\end{array}$ & 9865 & 1466 & 35 & 6,73 & 1995 & 6 & 0,902 & 1,394 & 0 & 0 & 0 & 144 & 1990 \\
\hline 17 & Journal of Community Health & 9787 & 1247 & 39 & 7,85 & 1994 & 19 & 1,573 & 1,765 & 0 & 0 & 0 & 145 & 1975 \\
\hline 18 & Psychology Public Policy and Law & 9354 & 508 & 45 & 18,41 & 1995 & 1 & 1,723 & 2,697 & 2 & 0 & 0 & 149 & 1995 \\
\hline 19 & Journal of Rural Health & 8759 & 943 & 37 & 9,29 & 1996 & 12 & 1,771 & 1,844 & 0 & 0 & 0 & 156 & 1985 \\
\hline 20 & Gesundheitswesen & 5518 & 1610 & 23 & 3,43 & 2000 & 62 & 0,624 & 0,621 & 0 & 0 & 0 & 187 & 1946 \\
\hline
\end{tabular}

Abbreviations: TC Total citations, TP Total papers, $H$ Hirsch index, TC/TP Average citations per paper, IF Impact factor, IF5 5-year impact factor, T50 Number of papers among the 50 most cited of the category, T200 and T200* Number of papers among the 200 most cited in all fields of health between 1990-2014 and before 1990, GR Global ranking considering all the journals

The most cited journal is the British Journal of General Practice, followed by the American Family Physician, the Journal of Family Practice, and Family Practice. The highest $h$-index is for the Journal of Family Practice. While these four papers are the most cited, Annals of Family Medicine is the journal with the highest impact factor, and 5-year impact factor. Among the 50 most cited papers in this category, the Journal of Family Practice has $34 \%$ of them, followed by Annals of Family Medicine with $18 \%$, the British Journal of General Practice with $16 \%$, and Family Practice with $12 \%$. There are two journals in the T200 ranking with one paper each, which are the Journal of Family Practice and Family Medicine.

\section{Comparison between fields}

Finally, let us provide a general picture of the publication and citation structure of each health category. Table 10 presents the results.

Epidemiology is the most influential category over the last 25 years with the highest number of citations, citations per paper, $h$-index and the largest number of articles among the 200 most cited before and after 1990. Public Health also obtains very remarkable results being the category with the largest number of articles. However, the category with the highest number of journals is Health Promotion and Health Behavior.

\section{Discussion and conclusions}

This study showed some remarkable viewpoints about health journals currently indexed in WoS database between 1990 and 2014. This analysis shows the results obtained by health journals under a wide range of bibliometric indicators. This is very useful to see the general results from a broader perspective than the Journal Citation Reports of WoS. Particularly, this is very useful for $\mathrm{PhD}$ students and newcomers in the field in order to get a general orientation of the leading journals in health research.

The results provide a general picture of the current position of the leading journals in this field for the nine categories analyzed, which can be rank in terms of total papers as follows: (1) Public Health, (2) Health Promotion and Health Behavior, (3) Medicine, (4) Environmental and Occupational Health, (5) Epidemiology, (6) Health Policy and Services, (7) Health Management and Economics, (8) Health Informatics, Engineering and Technology, and (9) Primary Care. The results indicate 
Table 7 Most influential journals in Medicine

\begin{tabular}{|c|c|c|c|c|c|c|c|c|c|c|c|c|c|c|}
\hline $\mathrm{R}$ & Journal name & TC & TP & $\mathrm{H}$ & TC/TP & Year & Volume & IF & IF5 & T50 & T200 & T200* & GR & $\begin{array}{l}\text { First } \\
\text { year }\end{array}$ \\
\hline 1 & American Journal of Tropical Medicine and Hygiene & 178865 & 7809 & 120 & 22,9 & 1990 & 42 & 2,736 & 2,947 & 9 & 1 & 1 & 6 & 1921 \\
\hline 2 & Journal of General Internal Medicine & 114351 & 4688 & 120 & 24,39 & 1990 & 5 & 3,423 & 3,744 & 14 & 3 & 3 & 13 & 1986 \\
\hline 3 & Academic Medicine & 92662 & 7000 & 98 & 13,24 & 1990 & 65 & 3,468 & 3,654 & 12 & 1 & 1 & 17 & 1926 \\
\hline 4 & $\begin{array}{l}\text { Transactions of the Royal Society of Tropical } \\
\text { Medicine and Hygiene }\end{array}$ & 84422 & 4933 & 83 & 17,11 & 1990 & 84 & 1,931 & 2,453 & 1 & 0 & 0 & 20 & 1908 \\
\hline 5 & Psychiatric Services & 74932 & 4731 & 91 & 15,84 & 1995 & 46 & 1,987 & 2,807 & 6 & 0 & 0 & 24 & 1950 \\
\hline 6 & Journal of Pain and Symptom Management & 71194 & 3586 & 95 & 19,85 & 1991 & 6 & 2,737 & 3,240 & 2 & 0 & 0 & 27 & 1986 \\
\hline 7 & Tropical Medicine \& International Health & 56435 & 3196 & 74 & 17,66 & 1996 & 1 & 2,302 & 2,953 & 0 & 0 & 0 & 35 & 1996 \\
\hline 8 & Nicotine \& Tobacco Research & 28496 & 1975 & 61 & 14,43 & 2003 & 5 & 2,805 & 3,125 & 2 & 0 & 0 & 69 & 1999 \\
\hline 9 & Palliative Medicine & 25715 & 1711 & 63 & 15,03 & 1995 & 9 & 2,845 & 3,565 & 0 & 0 & 0 & 71 & 1987 \\
\hline 10 & Journal of Womens Health & 20943 & 1932 & 49 & 10,84 & 1997 & 6 & 1,896 & 1,989 & 1 & 0 & 0 & 85 & 1992 \\
\hline 11 & $\begin{array}{l}\text { Journal of Manipulative and Physiological } \\
\text { Therapeutics }\end{array}$ & 18094 & 2429 & 45 & 7,45 & 1990 & 13 & 1,248 & 1,471 & 1 & 1 & 1 & 101 & 1978 \\
\hline 12 & Annals of Human Biology & 15402 & 1414 & 44 & 10,89 & 1990 & 17 & 1,148 & 1,515 & 0 & 0 & 0 & 111 & 1974 \\
\hline 13 & Journal of Evaluation in Clinical Practice & 13335 & 1785 & 44 & 7,47 & 1999 & 5 & 1,580 & 1,534 & 0 & 0 & 0 & 118 & 1995 \\
\hline 14 & Vector-Borne and Zoonotic Diseases & 13124 & 1248 & 41 & 10,52 & 2003 & 3 & 2,531 & 2,635 & 0 & 0 & 0 & 124 & 2001 \\
\hline 15 & Journal of Public Health Dentistry & 11983 & 1012 & 46 & 11,84 & 1990 & 50 & 1,644 & 1,653 & 0 & 0 & 0 & 130 & 1941 \\
\hline 16 & Journal of Palliative Medicine & 11142 & 1586 & 39 & 7,03 & 2005 & 8 & 2,063 & 2,446 & 0 & 0 & 0 & 138 & 1987 \\
\hline 17 & European Journal of Cancer Care & 9674 & 1056 & 40 & 9,16 & 1999 & 8 & 1,762 & 1,813 & 0 & 0 & 0 & 147 & 1992 \\
\hline 18 & Journal of Medical Screening & 9179 & 675 & 41 & 13,6 & 1998 & 5 & 2,722 & 2,234 & 0 & 0 & 0 & 150 & 1994 \\
\hline 19 & Implementation Science & 8777 & 883 & 39 & 9,94 & 2006 & 1 & 3,470 & 4,098 & 1 & 0 & 0 & 155 & 2006 \\
\hline 20 & Medical Anthropology Quarterly & 8041 & 608 & 40 & 13,23 & 1990 & 4 & 0,607 & 1,117 & 0 & 0 & 0 & 159 & 1987 \\
\hline
\end{tabular}

Abbreviations: TC Total citations, TP Total papers, $H$ Hirsch index, TC/TP Average citations per paper, IF Impact factor, IF5 5-year impact factor, T50 Number of papers among the 50 most cited of the category, T200 and T200* Number of papers among the 200 most cited in all fields of health between 1990-2014 and before 1990, GR Global ranking considering all the journals

Table 8 Most influential journals in Health Informatics, Engineering and Technology

\begin{tabular}{|c|c|c|c|c|c|c|c|c|c|c|c|c|c|c|}
\hline $\bar{R}$ & Journal name & TC & TP & $\mathrm{H}$ & $\mathrm{TC} / \mathrm{TP}$ & Year & Volume & $\mathrm{IF}$ & IF5 & T50 & T200 & T200* & GR & $\begin{array}{l}\text { First } \\
\text { year }\end{array}$ \\
\hline 1 & $\begin{array}{l}\text { Journal of the American Medical Informatics } \\
\text { Association }\end{array}$ & 47258 & 3139 & 94 & 15,06 & 2000 & 7 & 3,932 & 4,182 & 26 & 0 & 0 & 40 & 1994 \\
\hline 2 & Health Physics & 39417 & 4799 & 62 & 8,21 & 1990 & 58 & 0,774 & 1,105 & 4 & 1 & 1 & 52 & 1958 \\
\hline 3 & International Journal of Medical informatics & 22736 & 1696 & 55 & 13,41 & 1997 & 44 & 2,716 & - & 5 & 0 & 0 & 80 & 1970 \\
\hline 4 & Methods of information in Medicine & 17886 & 1704 & 47 & 10,5 & 1990 & 24 & 1,083 & 1,448 & 3 & 0 & 0 & 102 & 1962 \\
\hline 5 & Journal of Telemedicine and Telecare & 16334 & 1980 & 45 & 8,25 & 1998 & 4 & 1,736 & 1,661 & 0 & 0 & 0 & 106 & 1995 \\
\hline 6 & Journal of Medical Internet Research & 15683 & 1271 & 53 & 12,34 & 1999 & 1 & 4,669 & 5,724 & 4 & 0 & 0 & 108 & 1999 \\
\hline 7 & $\begin{array}{l}\text { International Journal of Technology Assessment in } \\
\text { Health Care }\end{array}$ & 15141 & 1346 & 45 & 11,25 & 1995 & 11 & 1,556 & 1,565 & 3 & 0 & 0 & 112 & 1985 \\
\hline 8 & Health Technology Assessment & 13181 & 650 & 56 & 20,28 & 2004 & 8 & 5,116 & 5,404 & 5 & 1 & 0 & 123 & 1997 \\
\hline 9 & Journal of Medical Systems & 5709 & 1188 & 26 & 4,81 & 1992 & 16 & 1,372 & 1,482 & 0 & 0 & 0 & 186 & 1977 \\
\hline 10 & International Journal of Health Geographics & 4350 & 485 & 28 & 8,97 & 2007 & 6 & 1,967 & 2,675 & 0 & 0 & 0 & 202 & 2002 \\
\hline
\end{tabular}

Abbreviations: TC Total citations, TP Total papers, $H$ Hirsch index, TC/TP Average citations per paper, IF Impact factor, IF5 5-year impact factor, T50 Number of papers among the 50 most cited of the category, T200 and T200* Number of papers among the 200 most cited in all fields of health between 1990-2014 and before 1990, GR Global ranking considering all the journals 
Table 9 Most influential journals in Primary Care

\begin{tabular}{lllllllllllllll}
\hline $\mathrm{R}$ & Journal name & $\mathrm{TC}$ & $\mathrm{TP}$ & $\mathrm{H}$ & $\mathrm{TC} / \mathrm{TP}$ & Year & Volume & IF & IF5 & T50 & T200 & T200* & GR & First year \\
\hline 1 & British Journal of General Practice & 47635 & 5770 & 74 & 8,26 & 1990 & 40 & 2,356 & 2,516 & 8 & 0 & 0 & 39 & 1953 \\
2 & American Family Physician & 43288 & 5726 & 62 & 7,56 & 1990 & 41 & 1,818 & 2,056 & 4 & 0 & 0 & 47 & 1970 \\
3 & Journal of Family Practice & 37511 & 3371 & 78 & 11,13 & 1990 & 30 & 0,735 & 0,729 & 17 & 1 & 1 & 55 & 1974 \\
4 & Family Practice & 35533 & 2322 & 66 & 15,3 & 1990 & 7 & 1,842 & 2,071 & 6 & 0 & 0 & 58 & 1984 \\
5 & Annals of Family Medicine & 16159 & 666 & 59 & 24,26 & 2004 & 2 & 4,570 & 5,250 & 9 & 0 & 0 & 107 & 2003 \\
6 & Canadian Family Physician & 13319 & 5046 & 35 & 2,64 & 1990 & 36 & 1,403 & 1,646 & 0 & 0 & 0 & 120 & 1955 \\
7 & Family Medicine & 10804 & 1546 & 38 & 6,99 & 2000 & 32 & 0,851 & 1,284 & 3 & 1 & 1 & 139 & 1981 \\
8 & Scandinavian Journal of Primary Health Care & 9132 & 866 & 35 & 10,55 & 1995 & 13 & 1,610 & 1,889 & 0 & 0 & 0 & 152 & 1983 \\
9 & Journal of the American Board of Family Medicine & 7230 & 898 & 32 & 8,05 & 2006 & 19 & 1,848 & 2,064 & 2 & 0 & 0 & 168 & 1988 \\
10 & Primary Care & 6856 & 1244 & 28 & 5,51 & 1990 & 17 & 0,833 & 1,084 & 1 & 0 & 0 & 174 & 1974
\end{tabular}

Abbreviations: TC Total citations, TP Total papers, $H$ Hirsch index, TC/TP Average citations per paper, IF Impact factor, IF5 5-year impact factor, T50 Number of papers among the 50 most cited of the category, T200 and T200* Number of papers among the 200 most cited in all fields of health between $1990-2014$ and before 1990, GR Global ranking considering all the journals

that Epidemiology is the most influential category although Public Health is the largest one. Focusing on journals, the American Journal of Epidemiology, Environmental Health Perspectives, American Journal of Public Health, and Social Science \& Medicine, have the highest number of citations which shows the largest influence in absolute terms. However, some other journals achieve better results when looking to other indicators. For example, according to the citations per paper ratio, the leading journals are Epidemiologic Reviews, Annual Review of Public Health, and Journal of Health and Social Behavior. This indicates that the journals considered in the study have different profiles with a wide variety of objectives. Almost all the leading journals are published in English although some journals may also publish in some other popular European languages including German, Spanish, French and Italian. Note that many journals have entered the WoS database during the last years although the most popular ones have been in the database for a long time.
In conclusion, by bibliometric methodology, the findings and suggestions of this study can help scientific researchers understand the performance and trends of health research globally. With the help of these findings researchers can make informed decisions of their research directions, in terms of identifying top journals of the discipline, and choose exchange platforms for their research. This study also helps to learn more about the subfields of health research, and identify emerging areas of research today such as public health, health promotion and health behavior and epidemiology, and also how most areas of health research have started to decline in number of citations from 2006.

From a general perspective, health research is a very broad area that includes a wide range of topics. This article classifies the material according to some of the most significant topics. However, it is worth noting that more specific topics could also be considered because each journal considers specific topics that do not depend on the topics followed by other journals. Moreover, the

Table 10 Global results for each category

\begin{tabular}{llllllll}
\hline Category name & NJ & H & TC & TP & TC/TP & T200 & T200* \\
\hline Public Health & 61 & 261 & 1.237 .899 & 83.365 & 14,85 & 38 & 28 \\
Environmental and Ocupational Health & 47 & 215 & 1.091 .045 & 73.649 & 14,81 & 25 & 6 \\
Health Management and Economics & 29 & 188 & 474.540 & 28.547 & 16,62 & 22 & 13 \\
Health Promotion and Health Behaviour & 73 & 218 & 1.156 .553 & 78.542 & 14,73 & 21 & 19 \\
Epidemiology & 25 & 325 & 1.806 .202 & 66.097 & 27,33 & 39 \\
Health Policy and Services & 40 & 172 & 484.055 & 37.911 & 12,77 & 8 & 89 \\
Medicine & 51 & 184 & 951.188 & 69.198 & 13,75 & 6 & 6 \\
Health Informatics, Engineering and Technology & 18 & 123 & 214.135 & 21.205 & 10,10 & 2 \\
Primary Health Care & 18 & 113 & 250.486 & 34.269 & 7,31 & 2 \\
\hline
\end{tabular}

Note that the columns of the T200 and the T200* do not sum up to 200 because some of the most cited papers were published in journals that currently are not indexed in WoS for several reasons

Abbreviations: NJ Number of journals 
study assigns each journal to one category but sometimes the journal could also be considered in another category. For solving this issue, the last column of each table (GR) considers the global ranking that each journal obtains when merging all the journals in the same list and ordering according to the number of citations. This allows comparison between journals from different categories. But note that each category or group of journals may have a different profile with a different volume of publications and citations. Therefore, it is not easy to compare journals with different topics and categories. Finally, recall that WoS has several limitations when classifying bibliographic material that should also be considered in this article [49]. Additionally, many other issues may affect research in this field including open access and electronic journals. Note that only those included in WoS are considered in the analysis.

\section{Additional file}

Additional file 1: Table S1. Public Health. Table S2. Environmental and Occupational Health. Table S3. Health Management and Economics. Table S4. Health Promotion and Health Behavior. Table S5.

Epidemiology. Table S6. Health Policy and Services. Table S7. Medicine.

Table S8. Health Informatics, Engineering and Technology (e-health). Table S9. Primary Health Care. (DOCX $153 \mathrm{~kb}$ )

\section{Acknowledgments}

Not applicable for this manuscript.

\section{Funding}

The authors have no support or funding to report.

\section{Availability of data and materials}

All data generated or analyzed during this study are included in this published article and its supplementary information file "Additional file 1".

\section{Authors' contribution}

The contribution of the author was as followed: JM developed the original research idea and questions, obtained the data for this study, conducted data analysis, interpreted the results, and wrote the manuscript. AN contributed to the original research idea and questions, conducted data analysis, interpreted the results, and contributed to the writing and revisions of the manuscript. Both authors read and approved the final manuscript.

\section{Authors' information}

Not applicable.

\section{Competing interests}

The authors declare that they have no competing interests.

\section{Consent for publication}

Not applicable.

Ethics approval and consent to participate

Not applicable.

Received: 17 December 2015 Accepted: 8 August 2016 Published online: 22 August 2016

\section{References}

1. Jakovljevic M, Ogura S. Health economics at the crossroads of centuries from the past to the future. Frontiers Public Health. 2016;4:115.
2. Porter D. The history of public health: current themes and approaches. Hygiea Int. 1999;1(1):9-21.

3. NIH - U.S. National Library of Medicine. Introduction to Health Services Research. http://www.nlm.nih.gov/nichsr/ihcm/02history/history01.html. Accessed 18 Aug 2015.

4. May R. The scientific wealth of nations. Science. 1997;275:793-6.

5. May R. The scientific investment of nations. Science. 1998;281:49-51.

6. Bliziotis IA, Paraschakis K, Vergidis PI, Karavasiou Al, Falagas ME. Worldwide trends in quantity and quality of published articles in the field of infectious diseases. BMC Infect Dis. 2005;5:16.

7. Michalopoulos A, Falagas ME. A bibliometric analysis of global research production in respiratory medicine. Chest. 2005;128:3993-8.

8. Rosmarakis ES, Vergidis PI, Soteriades ES, Paraschakis K, Papastamataki PA, Falagas ME. Estimates of global production in cardiovascular diseases research. Int J Cardiol. 2005:100(3):443-9.

9. Glover SW, Bowen SL. Bibliometric analysis of research published in tropical medicine and international health 1996-2003. Trop Med Int Health. 2004;9:1327-30.

10. Armfield NK, Edirippulige S, Cafferi L, Bradford N, Grey JW, Smith AC. Telemedicine-a bibliometric and content analysis of 17,932 publication records. Int J Med Inform. 2014:83:715-25.

11. Whipple E, Dixon B, McGowan J. Linking health information technology to patient safety and quality outcomes: a bibliometric analysis and review. Inform Health Soc Care. 2013;38(1):1-14.

12. Wen HC, Ho YS, Jian WS, Li HC, Elsa YH. Scientific production of electronic health record research, 1991-2005. Comput Methods Prog Biomed. 2007:86:191-6.

13. Boulos MN. On geography and medical journalology: a study of the geographical distribution of articles published in a leading medical informatics journal between 1999 and 2004. Int J Health Geog. 2005;4:7.

14. Verbeek J, Salmi J, Pasternack I, Jauhiainen M, Laamanen I, Schaafsma F, Hulshof C, Van Dijk F. A search strategy for occupational health intervention studies. Occup Environ Med. 2005;62:682-7.

15. Navarro A, Martin M. Scientific production and international collaboration in occupational health, 1992-2001. Scand J Work Environ Health. 2004;30:223-33.

16. Gehanno JF, Thirion B. How to select publications on occupational health: the usefulness of Medline and the impact factor. Occup Environ Med. 2000; 57(10):706-9.

17. Koseoglu MA, Akdeve E, Gedik I, Bertsch A. A bibliometric analysis of strategic management articles in healthcare management literature: past, present, and future. Int J Healthcare Manag. 2015;8(1):27-33.

18. Bouchard L, Albertinit M, Batista R, Montigny J. Research on health inequalities: a bibliometric analysis (1966-2014). Soc Sci Med. 2015;141:100-8.

19. Wagstaff A, Culyer A. Four decades of health economics through a bibliometric lens. J Health Econ. 2012;31(2):406-39.

20. Almeida-Filho N, Kawachi I, Pellegrini A, Dachs N. Research on health inequalities in Latin American and the Caribbean: bibliometric analysis (1971-2000) and descriptive content analysis (1971-1995). Am J Public Health. 2003;93(2):2037-43.

21. Yao Q, Lyu PH, Yang LP, Yao L, Liu ZY. Current performance and future trends in health care sciences and services research. Scientometrics. 2014;101:751-79.

22. Paganini JM, Raiher S. A bibliometric analysis of health services research publications: trends and characteristics. Technical Documents, Geneva, Alliance HPSR. 2006.

23. Pega F, Valentine N, Matheson D, Rasanathan K. Public social monitoring reports and their effect on a policy programme aimed at addressing the social determinants of health to improve health equity in New Zealand. Soc Sci Med. 2014;101:61-9.

24. Macías-Chapula CA. Comparative analysis of health public policy research results among Mexico, Chile and Argentina. Scientometrics. 2013;95:621-8.

25. López-Torres J, Basora J, Orozco D, Bellón JA. Bibliometric map of research done in primary care in Spain during the period 2008-2012 (In Spanish). Aten Primaria. 2014;46(10):541-8.

26. Carratalá MC, Orozco D, Gil VF, Navarro J, Quirce F, Merino J, Basora J. Bibliometric analysis of international scientific production on primary (In Spanish). Aten Primaria. 2012;44(11):651-8.

27. Nachega J, Uthman OA, Ho YS, Lo M, Anude C, Kayembe P, WabwireMangen F, Gomo E, Sow PS, Obike U, Kusiaku T, Mills E, Mayosi B, Ijsselmuiden C. Current status and future prospects of epidemiology and 
public health training and research in the WHO African region. Int J Epidemiol. 2012;41:1829-46.

28. Takahashi K, Hoshuyama T, Ikegami K, Itoh T, Higashi T, Okubo T. A bibliometric study of the trend in articles related to epidemiology published in occupational health journals. Occup Environ Med. 1996;53:433-8.

29. Rethlefsen ML, Aldrich AM. Environmental health citation patterns: mapping the literature 2008-2010. J Med Libr Assoc. 2013;101:47-54.

30. Smith S. Highly cited articles in environmental and occupational health, 1919-1960. Arch Environ Occup Health. 2009;64(1):32-42.

31. Smith S. A 30-year citation analysis of bibliometric trends at the archives of environmental health, 1975-2004. Arch Environ Occup Health. 2009;64(1):43-54.

32. Milat A, Bauman A, Redman S, Curac N. Public health research output from efficacy to dissemination: a bibliometric analysis. BMC Public Health. 2011:11:934

33. Porta M, Fernandez E, Murillo J, Alguacil J, Copete JL. The bibliographic "impact factor", the total number of citations and related bibliometric indicators: the need to focus on journals of public health and preventive medicine. Soz Praventivment. 2004;49:15-8.

34. Soteriades ES, Falagas ME. A bibliometric analysis in the fields of preventive medicine, occupational and environmental medicine, epidemiology, and public health. BMC Public Health. 2006;6:301.

35. Chinchilla Z, Zacca G, Vargas B, Moya F. Latin American scientific output in Public Health: combined analysis using bibliometric, socioeconomic and health indicators. Scientometrics. 2015;102(1):609-28.

36. Liu W, Tang L, Gu M, Hu G. Feature report on China: a bibliometric analysis of China-related articles. Scientometrics. 2015;102:503-17.

37. Kumara M, Edwards T, Stevens W, McCrossin T. Bibliometric analysis on Australian rural health publications from 2006 to 2012. Aust J Rural Health 2014;22:189-96.

38. Zacca G, Chinchilla Z, Vargas B, Moya F. Bibliometric analysis of regional Latin America's scientific output in public health through SCImago Journal \& Country Rank. BMC Public Health. 2014;14:632.

39. McCarthy M, Dyakova M, Clarke A. Public health research in the UK: a report with a European perspective. J Public Health. 2013;36(2):325-35.

40. Chuang KY, Chuang YC, Ho M, Ho YS. Bibliometric analysis of public health research in Africa: the overall trend and regional comparisons. S Afr J Sci. 2011;107(5/6):Art. \#309. 6 pages.

41. Dandona L, Raban MZ, Guggilla RK, Bhatnagar A, Dandona R. Trends of public health research output from India during 2001-2008. BMC Med. 2009;7:59.

42. Clarke A, Gatineau M, Grimaud O, Royer-Devaux S, Wyn-Roberts N, Le Bis I, Lewison G. A bibliometric overview of public health research in Europe. Eur J Pub Health. 2007:17(1):43-9.

43. Bar-llan J. Informetrics at the beginning of the 21 century - a review. Informetrics. 2008:2:1-52.

44. Broadus RN. Toward a definition of "Bibliometrics". Scientometrics. 1987;12:373-9.

45. Alonso S, Cabrerizo FJ, Herrera-Viedma E, Herrera F. H-index: a review focused on its variants, computation, and standardization for different scientific fields. J Informetrics. 2009;3:273-89.

46. Bonilla C, Merigó JM, Torres-Abad C. Economics in Latin America: a bibliometric analysis. Scientometrics. 2015;105(2):1239-52.

47. Merigó JM, Mas-Tur A, Tierno-Roig N, Ribeiro-Soriano D. A bibliometric overview of the Journal of Business Research between 1973 and 2014. J Bus Res. 2015;68(12):2645-53.

48. Hirsch JE. An index to quantify an individual's scientific research output. Proc Natl Acad Sci U S A. 2005;102:16569-72.

49. Merigó JM, Gil-Lafuente AM, Yager RR. An overview of fuzzy research with bibliometric indicators. Appl Soft Comput. 2015:27:420-33.

50. WHO. http://www.who.int/healthpromotion/about/HPR\%20Glossary\%201998. pdf. Accessed 18 Aug 2015

\section{Submit your next manuscript to BioMed Central and we will help you at every step:}

- We accept pre-submission inquiries

- Our selector tool helps you to find the most relevant journal

- We provide round the clock customer support

- Convenient online submission

- Thorough peer review

- Inclusion in PubMed and all major indexing services

- Maximum visibility for your research

Submit your manuscript at www.biomedcentral.com/submit
Biomed Central 